\title{
PENGEMBANGAN EKONOMI KREATIF SEBAGAI PARADIPLOMASI KOTA METROPOLITAN SEOUL
}

\author{
Gilang Nur Alam¹, Rizka Maharani ${ }^{2}$, RMT Nurhasan Affandi ${ }^{3}$, Windy \\ Dermawan $^{4}$
}

${ }^{1}$ Program Studi Ilmu Hubungan Internasional Fakultas Ilmu Sosial dan Ilmu Politik Universitas Padjajaran, g.n.alam@unpad.ac.id

${ }^{2}$ Program Studi Ilmu Hubungan Internasional Fakultas Ilmu Sosial dan Ilmu Politik Universitas Padjajaran

${ }^{3}$ Program Studi Ilmu Hubungan Internasional Fakultas Ilmu Sosial dan Ilmu Politik Universitas Padjajaran

${ }^{4}$ Program Studi Ilmu Hubungan Internasional Fakultas Ilmu Sosial dan Ilmu Politik Universitas Padjajaran

\begin{abstract}
Seoul Metropolitan City is one of the metropolitan cities in South Korea, which able to perceive its interest with self-government in international activities. Seoul Metropolitan City government has implemented paradiplomacy to develop its creative economy which is limited to aspects of music, drama, and fashion. This article uses qualitative methods with literature studies to support the required data. This article also seeks to describe the paradiplomacy carried out by the Seoul Metropolitan City government with self-government in a unitary state with a literature review covering transgovernmentalism, foreign relations, paradiplomacy, and creative economy. Besides, the authors also argue that the Seoul Metropolitan City government could optimize its potential with policies or actions taken by the Seoul Metropolitan City government on the aspects of music, drama, and fashion towards the global public.
\end{abstract}

Keywords: Creative Economy, Seoul Metropolitan City, Paradiplomacy, Foreign Relations

\section{PENDAHULUAN}

Sebagai salah satu kota metropolitan di Korea Selatan, Kota Metropolitan Seoul merupakan salah satu wilayah yang mendapatkan self-government dari pemerintah nasional. Kepemilikan self-government berarti 
suatu wilayah memiliki hak serta kewajiban untuk membuat regulasi yang mencakup komponen penting dari public affairs di bawah tanggung jawab dan kepentingan dari masyarakat setempat. Korea Selatan merupakan negara kesatuan dengan pembagian sistem tata kelola pemerintahannya menyerupai negara federal, di mana beberapa wilayah mendapatkan hak berupa self-government untuk mengelola pemerintahannya tanpa ada intervensi dari pemerintah nasional. Pemerintah nasional bertindak sebagai regulator, sehingga pemerintah subnasional menjalankan aktivitas internasional berada pada alur yang sesuai dengan pemerintah nasional. (Byeonghee, 2018)

Dalam hal ini, pemerintah Kota Metropolitan Seoul berupaya untuk mengembangkan ekonomi kreatifnya, artikel ini membatasi pada aspek musik, drama, dan fashion, yang sesuai dengan tujuan dari pemerintah Kota Metropolitan Seoul. Tujuan pemerintah Kota Metropolitan Seoul dalam mengembangkan ekonomi kreatif adalah 1) berupaya untuk menciptakan pekerjaan baru dan pasar melalui industri kreatif dan ekonomi, 2) meningkatkan peranan ekonomi melalui ekonomi kreatif, dan 3) menciptakan masyarakat kreatif (United Nations Conference on Trade and Development, 2017). Selain itu, pemerintah Kota Metropolitan Seoul juga memiliki kepentingan dalam melakukan pengembangan ekonomi kreatif sebagai salah satu UNESCO creative cities sejak Juli 2010. Kepentingan Kota Metropolitan Seoul tersebut dilakukan dengan kebijakan atau aksi yang ditujukan pada publik global melalui kepemilikan legal personality ${ }^{1}$ I Seoul U (Seoul Metropolitan Government, 2010) (UNESCO, 2017). I Seoul U digunakan oleh pemerintah Kota Metropolitan Seoul untuk menarik perhatian global dengan memiliki makna bahwa Kota Metropolitan Seoul sebagai pusat hubungan antarmanusia di seluruh dunia, di mana Kota Metropolitan Seoul merupakan wilayah yang mempertemukan pembangunan kota yang modern dengan

\footnotetext{
${ }^{1}$ Merujuk pada Tewari (2017), legal personality adalah kepemilikan hak istimewa oleh pemerintah subnasional dalam menjalankan suatu tujuan atau kepentingan dalam melakukan aktivitas internasional.
} 
budaya tradisional dan terhubung dengan harmoni (Seoul Metropolitan Government, n.d.).

Upaya paradiplomasi yang dilakukan oleh pemerintah Kota Metropolitan Seoul dalam pengembangan ekonomi kreatif dapat dilihat dari kebijakan atau aksi pada aspek musik, drama, dan fashion. Pemerintah Kota Metropolitan Seoul berupaya untuk melakukan expression of identity dalam melakukan paradiplomasi, sehingga pemerintah Kota Metropolitan Seoul juga menyediakan berbagai informasi di laman resminya dengan menyediakan beberapa bahasa, seperti Bahasa Inggris, Bahasa Prancis, Bahasa Spanyol, Bahasa Jepang, dan Mandarin, dimana hal tersebut menjadi salah satu aksi yang dilakukan untuk melakukan pengembangan terhadap ekonomi kreatifnya pada publik global, terutama pada aspek musik, drama, dan fashion.

Studi terdahulu yang ditulis oleh Rodrigues \& Mattioli (2017) dan Grydehøj (2014) memaparkan mengenai paradiplomasi didasari atas masyarakat multikultural dan pemerintah subnasional yang melakukan paradiplomasi terbatas pada upaya menyejahterakan masyarakatnya tanpa mengoptimasi potensi wilayah subnasional tersebut. Studi lainnya mengenai ekonomi kreatif sudah banyak diulas dan menjadi hirauan para akademisi, diantaranya yaitu kajian Delanova et al., (2018) mengkaji ekonomi kreatif dalam ikhtiar kerjasama sister city Bandung-Petaling Jaya sebagai bentuk peningkatan industri kreatif di kedua aktor subnegara tersebut. Bahkan, kajian Delanova (2018) menunjukkan bahwa pengembangan industri kreatif sebagai bentuk antisipasi suatu aktor subnegara di dalam memasukan area perdagangan bebas. Harikesa (2020) menunjukkan program-program Badan Ekonomi Kreatif Indonesia di dalam memperkuat sektor ekonomi kreatif sebagai upaya menghadapi era Revolusi Industri 4.0. Budaya industri ekonomi kreatif pun sudah menginternasionalisasi, seperti yang ditunjukkan Cool Japan dan Korean Wave melalui kajiannya Ramsey (2018). Isu ekonomi kreatif tidak hanya membawa ketertarikan bagi aktor negara, bahkan aktor 
subnegara pun memiliki hirauan untuk pengembangannya. Burhan (2017) menunjukkan bahwa Kota Makassar berupaya mengembangkan ekonomi kreatif yang berbasis pada budaya dalam menghadapi Masyarakat Ekonomi ASEAN. Bahkan, kajian Wibowo (2018) menemukan bahwa pada level desa (BUMDES), pengembangan ekonomi kreatif menjadi ketertarikan tersendiri dalam meningkatkan koperasi berbasis teknologi informasi.

Kota Metropolitan Seoul merupakan salah satu kota metropolitan di Korea Selatan yang memiliki self-government sebagai bentuk pemberian wewenang dari pemerintah nasional, sedangkan Korea Selatan merupakan negara kesatuan yang biasanya pemerintah nasional memiliki kuasa penuh atas pemerintah subnasional. Namun, Kota Metropolitan Seoul dapat melakukan aktivitas internasional dengan tujuan untuk mencapai kepentingannya untuk mengoptimalisasikan potensi yang dimiliki, dimana hal tersebut tidak dicampuri oleh pemerintah nasional karena pengembangan ekonomi kreatif dengan paradiplomasi merupakan agenda dari pemerintah Kota Metropolitan Seoul.

Penulisan artikel ini didasari atas upaya pemerintah Kota Metropolitan Seoul dalam melakukan paradiplomasi dengan tujuan untuk menyejahterakan masyarakatnya serta mengoptimalisasikan potensi yang dimiliki. Selain itu, pemerintah Kota Metropolitan Seoul dalam melakukan paradiplomasi juga tidak bertentangan dengan kepentingan pemerintah nasional, dimana kepentingan dari pemerintah Korea Selatan dalam melakukan diplomasi budaya adalah menyebarkan atraksi budaya, meningkatkan citra bangsa melalui aset budaya, dan memperkuat komunikasi dua arah melalui pertukaran budaya (Ministry of Foreign Affairs of Republic of Korea, n.d.).

Berdasarkan hal tersebut, penulis tertarik untuk membahas paradiplomasi yang dilakukan oleh pemerintah Kota Metropolitan Seoul dalam mengembangkan ekonomi kreatif dengan tata kelola pemerintahan yang ada di Korea Selatan. Selain itu, tulisan ini juga bertujuan untuk memaparkan 
bagaimana pemerintah Kota Metropolitan Seoul dalam melakukan paradiplomasi dalam pengembangan ekonomi kreatifnya.

Dalam penulisan artikel ini, penulis menggunakan beberapa konsep dalam Hubungan Internasional, yaitu transgovernmentalisme, hubungan luar negeri, paradiplomasi, dan ekonomi kreatif. Transgovernmentalisme merupakan interaksi yang dilakukan oleh suatu unit konstituen lain di suatu wilayah, karena adanya pemberian wewenang dari pemerintah nasional ke pemerintah subnasional (Nye \& Keohane, 2010). Hubungan luar negeri adalah pemerintah subnasional berupaya untuk mengembangkan potensi wilayahnya dengan tujuan dasar untuk menyejahterakan masyarakat (Nye \& Keohane, 2010). Paradiplomasi adalah pemerintah subnasional berupaya untuk mengembangkan potensi wilayahnya dengan tujuan dasar untuk menyejahterakan masyarakat (Lequesne \& Paquin, 2017). Ekonomi kreatif adalah hubungan hubungan antara kreativitas dan ekonomi yang dikombinasikan untuk menciptakan nilai dan kekayaan (Suciu, 2008). Ekonomi kreatif erat kaitannya dengan industri kreatif dan budaya, sehingga dua aspek tersebut merupakan produk dari ekonomi kreatif itu sendiri (Bocella \& Salerno, 2016).

Penulis juga menggunakan metode penelitian kualitatif yang merujuk pada Christopher Lamont dalam bukunya yang berjudul "Research Methods in International Relations", dimana suatu penulisan harus melibatkan penulis dan menggunakan berbagai kajian ilmu terkait. Oleh karena itu, penulis juga menggunakan kajian studi Hubungan Internasional untuk membantu penulis di dalam menuliskan artikel ini (Lamont, 2015).

\section{PARADIPLOMASI KOTA METROPOLITAN SEOUL PADA ASPEK MUSIK}

I Seoul U merupakan upaya dari pemerintah Kota Metropolitan Seoul sebagai bentuk pengekspresian identitas di dalam melakukan paradiplomasi. Selain itu, I Seoul U (나와 너의 서울) juga memiliki makna bahwa di antara 
saya (I) dan kamu (U) terhubung dengan Kota Metropolitan Seoul, sehingga hal tersebut menjadi strategi dari pemerintah Kota Metropolitan Seoul untuk menarik perhatian publik global di dalam pengembangan ekonomi kreatif pada aspek musik, drama, dan fashion (Byeonghee, 2018).

Kota Metropolitan Seoul dalam melakukan paradiplomasinya didasari atas tujuan dan kepentingan Kota Metropolitan Seoul sebagai salah satu UNESCO creative cities. Di dalam penulisan artikel ini, penulis membatasi pada aspek musik, drama, dan fashion. Pemerintah Kota Metropolitan Seoul dalam melakukan pengembangan ekonomi kreatifnya membuat beberapa instansi atau lembaga sebagai pengimplementasian dari tujuan dan kepentingan dalam pengembangan ekonomi kreatif, seperti Seoul Tourism Organization dengan penamaan Visit Seoul (Byeonghee, 2018). Perkembangan ekonomi kreatif Kota Metropolitan Seoul dapat dilihat dari setiap aspek, dalam aspek musik, pemerintah Kota Metropolitan Seoul berupaya untuk bekerja sama dengan salah satu agensi K-Pop Idol terbesar, yaitu SM Entertainment, dalam pengadaan konser di Tiongkok, Asia Tenggara, dan Taiwan pada Asian Concert Tour di tahun 2011. Di dalam konser tersebut, pemerintah Kota Metropolitan Seoul menayangkan video mengenai Kota Metropolitan Seoul untuk menarik perhatian dari publik global yang hadir di konser agar dapat datang ke Kota Metropolitan Seoul sebagai salah satu bentuk pengimplementasian dari paradiplomasi pada aspek musik (Seoul Metropolitan Government, 2011). Pada tahun 2013, pemerintah Kota Metropolitan Seoul juga berhasil menarik perhatian hallyu fans sejumlah 9,3 juta setelah bekerja sama dengan SM Entertainment (Jhoo, 2015). Oleh karena itu, pemerintah Kota Metropolitan Seoul menginvestasikan sebanyak 482 miliar won untuk menjadikan Kota Metropolitan Seoul sebagai pusat musik (KBS World, 2019).

Setelah adanya perkembangan yang signifikan dari paradiplomasi yang dilakukan oleh pemerintah Kota Metropolitan Seoul pada aspek musik, untuk mengoptimalkan kembali potensi yang dimiliki, pemerintah Kota Metropolitan 
Seoul memanfaatkan peran $K$-Pop Idol sebagai pengimplementasian strategi dari paradiplomasi yang dilakukan. K-Pop Idol dari berbagai agensi, seperti SM Entertainment, JYP Entertainment, dan Fantagio Entertainment, untuk bekerja sama dengan pemerintah Kota Metropolitan Seoul dalam menarik perhatian publik global. Peran dari K-Pop Idol sebagai bentuk representasi dari tujuan dan kepentingan Kota Metropolitan Seoul dapat dilihat pada commercial film $(\mathrm{CF})$ mengenai I Seoul U yang dibintangi oleh $\mathrm{BTS}^{2}$. Selain itu, $\mathrm{Exo}^{3}$ juga turut menjadi salah satu K-Pop Idol yang mempromosikan Kota Metropolitan Seoul dalam Visit Seoul, serta Twice ${ }^{4}$ yang membintangi CF mengenai I Seoul $\mathrm{U}$ yang diunggah ke sosial media untuk menarik para penggemar mereka agar datang ke Kota Metropolitan Seoul. Hal tersebut merupakan strategi dari pemerintah Kota Metropolitan Seoul dalam melakukan paradiplomasi yang sesuai dengan tujuan dan kepentingannya dalam mengembangkan ekonomi kreatif terhadap publik global.

Lalu, pemerintah Kota Metropolitan Seoul juga mengadakan Seoul Music Festival sebagai bentuk aksi dalam melakukan paradiplomasi untuk menarik perhatian publik global. Bentuk kegiatan tersebut dibentuk dengan adanya talk concert antara idol dan para penggemarnya (Korea Tourism Organization, 2019). Seoul Music Festival diadakan di Gwanghwamun Square, Kota Metropolitan Seoul, yang merupakan menjadi rencana anggaran acara lima tahunan pemerintah Kota Metropolitan Seoul untuk memajukan industri musik Korea Selatan (Yonhap News Agency, 2019).

\section{PARADIPLOMASI KOTA METROPOLITAN SEOUL PADA ASPEK DRAMA}

Selain pada aspek musik, pemerintah Kota Metropolitan Seoul juga melakukan pengembangan ekonomi kreatifnya pada aspek drama yang disebarkan secara transnasional. Drama korea, atau dikenal dengan K-Drama,

\footnotetext{
${ }^{2}$ BTS adalah salah satu K-Pop Idol yang berada di agensi Bighit Entertainment, Kota Metropolitan Seoul.

${ }^{3}$ Exo adalah salah satu K-Pop Idol yang berada di agensi SM Entertainment, Kota Metropolitan Seoul.

${ }^{4}$ Twice adalah salah satu K-Pop Idol yang berada di agensi JYP Entertainment, Kota Metropolitan Seoul.
} 
menunjukkan aktivitas masyarakat Kota Metropolitan Seoul dan mendorong publik global untuk datang ke Korea Selatan, terutama Kota Metropolitan Seoul. Perkembangan pada aspek drama dimulai pada tahun 2011, di mana pemerintah Kota Metropolitan Seoul mempromosikan kotanya dengan tayangan drama yang berjudul 'My Princess' di China Entertainment TV (CETV) (Seoul Metropolitan Government, 2011). Selain itu, pemerintah Kota Metropolitan Seoul juga bekerja sama dengan SM Entertainment untuk melakukan joint venture dengan Trans Media pada tahun 2018 untuk menayangkan K-Drama di Trans Tv. Penayangan K-Drama membuat publik global terhubung dengan ikatan antara aktor dan aktris di dalam budaya lokal, sehingga muncul perasaan senang atau empati untuk datang ke Kota Metropolitan Seoul agar dapat merasakan suasana yang ditunjukkan pada suatu K-Drama (Teh \& Goh, 2016). Hal tersebut ditunjukkan pada salah satu spot pengambilan scene pada drama 'Fight for My Way' di Seoullo 7017.

K-Drama menjadi salah satu upaya pengimplementasian Kota Metropolitan Seoul dalam menarik perhatian publik global. Hal ini ditunjukkan dengan adanya Seoullo 7017 setelah pengambilan scene pada drama 'Fight for My Way' untuk mencapai comprehensive development plan bagi masyarakat Kota Metropolitan Seoul (Sangkyun et al., 2009). Pemerintah Kota Metropolitan Seoul melakukan hubungan luar negeri dengan paradiplomasi menghasilkan peningkatan wisatawan yang datang ke Kota Metropolitan Seoul. Seperti yang tertulis di laman resmi pemerintahan Kota Metropolitan Seoul, sebanyak 13 juta wisatawan datang ke Kota Metropolitan Seoul pada tahun 2016 dan sejumlah 27 juta wisatawan datang ke Kota Metropolitan Seoul pada tahun 2017 (The Association Magazine, 2018). Oleh karena itu, pemerintah Kota Metropolitan Seoul berupaya untuk merestrukturisasi Seoullo 7017 sebagai skygarden yang menghubungkan beberapa titik melalui Seoul Station. Hal tersebut ditujukan untuk mencapai Kota Metropolitan Seoul dengan tingkat MICE (Meetings, Incentive tours, 
Conventions, and Exhibitions) tertinggi di dunia yang diimplementasikan sebagai tempat pengadaan konvensi internasional dan mempromosikan pariwisata Kota Metropolitan Seoul (Seoul Metropolitan Government, n.d.).

\section{PARADIPLOMASI KOTA METROPOLITAN SEOUL PADA ASPEK FASHION}

Paradiplomasi yang dilakukan oleh pemerintah Kota Metropolitan Seoul dalam mengembangkan ekonomi kreatif pada aspek fashion adalah dengan pengadaan Seoul Fashion Week yang diadakan di bulan Maret dan Oktober setiap tahunnya (spring/summer dan autumn/winter collection) (Week, 2020). Seoul Fashion Week diorganisatori oleh Seoul Design Foundation. Pemerintah Kota Metropolitan Seoul mengadakan Seoul Fashion Week bertujuan agar Kota Metropolitan Seoul dapat bersanding dengan Milan, New York, Paris, dan London sebagai kota fashion ternama. Pengadaan Seoul Fashion Week oleh pemerintah Kota Metropolitan Seoul tidak berorientasi pada keuntungan, sehingga Seoul Fashion Week sebagai acara peragaan busana dapat membantu desainer lokal dari Kota Metropolitan Seoul (Hye Eun, 2015).

Pemerintah Kota Metropolitan Seoul telah mengadakan Seoul Fashion Week sejak tahun 2006. Pada tahun 2010, Seoul Fashion Week diadakan di IFC Mall, Yeuido, Kota Metropolitan Seoul dan tidak mengundang international press maupun international buyers, sehingga cakupannya masih secara lokal. Pada tahun 2014, Seoul Fashion Week diadakan di Dongdaemun Design Plaza (DDP) sebagai warisan nasional Korea Selatan dan mulai mengundang international press, international buyers, domestic press, dan domestic buyers (Jimenéz, Lorena; Kim, 2019). Seoul Fashion Week juga ditujukan agar para desainer lokal terdorong untuk memasarkan rancangannya ke pasar internasional dengan dukungan dan bantuan dari pemerintah Kota Metropolitan Seoul maupun Seoul Design Foundation, serta Seoul Fashion Week diadakan untuk menarik perhatian publik global, dalam hal ini adalah 
fashionistas, untuk datang ke Kota Metropolitan Seoul dan melihat fashion dari desainer lokal (Government, 2019).

\section{UPAYA SEOUL DALAM PENGEMBANGAN EKONOMI KREATIF PADA ASPEK MUSIK, DRAMA, DAN FASHION}

Terdapat konsep yang paling mendasar dalam kegiatan paradiplomasi pemerintah kota metropolitan Seoul, yakni konsep transgovernmentalisme serta hubungan luar negeri. Penulis beranggapan bahwa transgovernmentalisme yang dimaksud adalah ketika pemerintah Kota Metropolitan Seoul melakukan pemberian wewenang berupa self-government dari pemerintah nasional. Ini disebabkan karena Korea Selatan memiliki tata kelola pemerintahan yang menyerupai negara federal, dimana beberapa tatanan pemerintahannya mendapatkan self-government, seperti provinces, municipal government, dan administrative district. Kota Metropolitan Seoul merupakan special city dan salah satu kota metropolitan yang dapat mengatur wilayahnya tanpa ada intervensi dari pemerintah nasional.

Pemerintah nasional tidak memberikan suatu instruksi atau kebijakan terhadap pemerintah subnasional untuk melakukan aktivitas internasional, karena pengembangan ekonomi kreatif Kota Metropolitan Seoul merupakan agenda dari pemerintah subnasional. Pemerintah nasional akan turut memberikan instruksi atau kebijakan terhadap pemerintah subnasional ketika pemerintah nasional mendelegasikan tugasnya ke pemerintah subnasional (Kwang-Kook, Park; Wonhee, Lee; Seok-Hwan, 2016). Lalu, penulis berpendapat bahwa pemerintah Kota Metropolitan Seoul menerapkan transgovernmental policy coordination, karena terdapat aktivitas akibat adanya implementasi dari suatu kebijakan yang dibuat. Dalam hal ini, pemerintah Kota Metropolitan Seoul melakukan beberapa aktivitas akibat adanya kebijakan yang berasal dari tujuan dan kepentingan dari Kota Metropolitan Seoul sendiri, terutama pada aspek musik, drama, dan fashion yang akan 
dijelaskan lebih lanjut di dalam paradiplomasi yang dilakukan oleh pemerintah Kota Metropolitan Seoul.

Pemerintah Kota Metropolitan Seoul juga melakukan hubungan luar negeri dalam menerapkan paradiplomasi untuk melakukan pengembangan terhadap ekonomi kreatif. Hubungan luar negeri pemerintah Kota Metropolitan Seoul dilakukan dengan tiga tahap (Hönke, 2014), yaitu 1) fase eksplorasi dengan melihat adanya keterhubungan antara publik global dengan ekonomi kreatif Kota Metropolitan Seoul, dalam hal ini adalah aspek musik, drama, dan fashion, 2) fase konsolidasi, dimana pemerintah Kota Metropolitan Seoul memiliki tujuan dan kepentingan untuk melakukan pengembangan ekonomi kreatif pada aspek musik, drama, dan fashion. Hal tersebut dilakukan atas dasar untuk menyejahterakan masyarakatnya dengan melibatkan masyarakat Kota Metropolitan Seoul untuk ikut mempromosikan potensi wilayahnya dengan I Seoul U sebagai legal personality dari Kota Metropolitan Seoul, dan 3) fase integrasi.

Penulis berpendapat bahwa hubungan luar negeri yang dilakukan dengan paradiplomasi disadari secara langsung maupun tidak langsung oleh publik global dan pemerintah Kota Metropolitan Seoul, karena aksi yang dilakukan oleh pemerintah Kota Metropolitan Seoul dalam mengembangkan ekonomi kreatifnya ditujukan pada publik global dan kontribusi dari publik global memberikan keuntungan terhadap pemerintah Kota Metropolitan Seoul, seperti halnya dalam bidang pariwisata. Menurut German Offices of International Affairs, international network dan city branding/marketing merupakan salah satu upaya yang dilakukan oleh pemerintah subnasional dalam melakukan hubungan luar negeri.

Hal ini dilakukan oleh pemerintah Kota Metropolitan Seoul dengan 1) upaya untuk mempromosikan wilayahnya dengan legal personality I Seoul U, 2) mengimplementasikan pelayanan yang ditujukan pada publik global dengan mengadakan beberapa aksi sebagai salah satu bentuk hubungan luar negeri 
yang dilakukan dengan paradiplomasi, 3) kebijakan yang diterapkan oleh pemerintah Kota Metropolitan Seoul dalam mengembangkan ekonomi kreatif pada aspek musik, drama, dan fashion ditujukan untuk publik global, dan 4) adanya financial inducement dari pemerintah Kota Metropolitan Seoul untuk mengadakan aksi dari hubungan luar negeri dalam mengadakan paradiplomasi dengan melakukan investasi terhadap aspek ekonomi kreatif yang dikembangkan, yaitu musik, drama, dan fashion. Hubungan luar negeri yang dilakukan oleh pemerintah Kota Metropolitan Seoul dalam mengembangkan ekonomi kreatifnya juga terjadi karena adanya good local governance antara pemerintah Kota Metropolitan Seoul dan pemerintah nasional, dimana terdapat pembagian kekuasaan di antara kedua pemerintahan, sehingga pemerintah Kota Metropolitan Seoul dapat melakukan aktivitas internasional untuk mencapai kepentingan subnasionalnya.

Aspek musik, drama, dan fashion termasuk ke dalam ekonomi kreatif menurut David Throsby (2008), di mana musik termasuk ke dalam core cultural expression, drama termasuk ke dalam wider cultural industries, dan fashion masuk ke dalam related industries. Ekonomi kreatif memang erat kaitannya dengan industri kreatif, di mana industri kreatif merupakan bagian dari ekonomi kreatif (Throsby, 2008). Namun, penulisan artikel ini menekankan pada ekonomi kreatif yang dapat dikembangkan untuk melakukan expression of identity dari pemerintah Kota Metropolitan Seoul.

Selain itu, strategi yang dilakukan dalam paradiplomasi dikembalikan ke masing-masing pemerintah subnasional sesuai dengan kepentingannya. Korea Selatan dikenal dengan hallyu wave-nya, serta beberapa aspek K-Pop juga dilakukan di Kota Metropolitan Seoul, sehingga strategi yang dilakukan oleh pemerintah Kota Metropolitan Seoul dalam melakukan paradiplomasi memanfaatkan keberadaan K-Pop Idol maupun aspek-aspek lainnya yang menjadi identitas dari Kota Metropolitan Seoul itu sendiri, yaitu Seoul Music Festival, Seoullo 7017, dan Seoul Fashion Week. 


\section{SEOUL U SEBAGA LEGAL PERSONALITY PEMERINTAH KOTA METROPOLITAN SEOUL DALAM MELAKUKAN PARADIPLOMASI}

I Seoul U merupakan legal personality Kota Metropolitan Seoul dalam melakukan paradiplomasi pada pengembangan ekonomi kreatif yang ditujukan untuk publik global. Penggunaan legal personality ini dimulai sejak tahun 2015 yang menggantikan legal personality sebelumnya, yaitu Hi, Seoul (Seoul Metropolitan Government, 2010). Paradiplomasi yang dilakukan oleh pemerintah Kota Metropolitan Seoul dalam upayanya mengembangkan ekonomi kreatif melibatkan pemerintah dan masyarakat Kota Metropolitan Seoul, serta organisasi yang menunjang pemerintah Kota Metropolitan Seoul dalam melakukan paradiplomasi, baik di dalam maupun di luar batas wilayah Kota Metropolitan Seoul. Selain itu, kelompok individu yang bergerak di bidang musik dan fashion juga turut terlibat dalam memberdayakan sumber daya yang dimiliki di Kota Metropolitan Seoul. Pemberdayaan sumber daya tersebut ditujukan untuk memaksimalkan potensi yang dimiliki untuk mampu mengajak partisipasi publik global dalam segala bentuk kebijakan yang dilakukan oleh Kota Metropolitan Seoul dalam melakukan paradiplomasi (Seoul Metropolitan Government, 2011).

Upaya penggunaan legal personality I Seoul U oleh pemerintah Kota Metropolitan Seoul menggunakan makna Our Seoul Story untuk mendefinisikan tujuan maupun kepentingan dari Kota Metropolitan Seoul dalam melakukan paradiplomasi. I Seoul U memiliki tiga filosofi, yaitu 1) coexistence bermakna masyarakat Kota Metropolitan Seoul yang berintegrasi dengan kepentingan pemerintah Kota Metropolitan Seoul, khususnya pada aspek ekonomi kreatif. Hal ini menunjukkan bahwa adanya peran dari masyarakat Kota Metropolitan Seoul yang turut serta membantu pemerintah dalam melakukan paradiplomasi, 2) passion memiliki makna bahwa pemerintah Kota Metropolitan Seoul mampu merepresentasikan masa lampau, 
saat ini, dan masa yang akan datang, serta 3) relaxation merepresentasikan Kota Metropolitan Seoul yang memiliki harmoni alam dan nasional. Hal ini ditunjukkan dengan adanya tempat bersejarah dan gedung pencakar langit (Byeonghee, 2018).

I Seoul U juga digunakan pada penyematan pelaksanaan kebijakan yang dilakukan oleh pemerintah Kota Metropolitan Seoul, khususnya pada pengembangan ekonomi kreatif. Hal ini dapat dilihat dari pelaksanaan paradiplomasi pada tiap aspek, yaitu musik, drama, dan fashion. Hal ini dikarenakan I Seoul U telah dianggap menjadi identitas yang melekat dari Kota Metropolitan Seoul itu sendiri (Seoul Metropolitan Government, n.d.). Selain itu, legal personality I Seoul U juga dianggap sebagai upaya positif dari pemerintah Kota Metropolitan Seoul dalam melakukan paradiplomasi yang ditujukan untuk publik global. Hal ini juga ditunjang dengan adanya kebijakan yang memang ditujukan untuk publik global, sehingga paradiplomasi yang dilakukan oleh pemerintah Kota Metropolitan Seoul dapat menjangkau publik global, baik masyarakat Kota Metropolitan Seoul yang berkewarganegaraan Korea Selatan maupun masyarakat asing yang menetap di sana (Seoul Metropolitan Government, n.d.).

\section{KESIMPULAN}

Paradiplomasi merupakan upaya yang dilakukan oleh pemerintah subnasional untuk mencapai kepentingannya di dalam aktivitas internasional. Kota Metropolitan Seoul sebagai salah satu kota metropolitan di Korea Selatan melakukan paradiplomasi untuk melakukan pengembangan ekonomi kreatif. Kota Metropolitan Seoul memiliki kewenangan untuk mengatur wilayahnya sendiri, yang dikenal sebagai self-government, oleh pemerintah nasional dalam mencapai kepentingannya. Pemerintah nasional Korea Selatan tidak mencampuri urusan pemerintah subnasionalnya di dalam melakukan aktivitas internasional, apabila aktivitas tersebut merupakan agenda dari 
wilayah subnasional. Pemerintah nasional akan turut serta dalam aktivitas internasional ketika terdapat pendelegasian tugas ke pemerintah subnasional.

Ekonomi kreatif merupakan tujuan dan kepentingan dari Kota Metropolitan Seoul sebagai UNESCO creative cities dan kepemilikan legal personality I Seoul U untuk menarik perhatian publik global. Aspek-aspek ekonomi kreatif tersebut di dalam artikel ini dibatasi pada aspek musik, drama, dan fashion. Pemerintah Kota Metropolitan Seoul dalam melakukan paradiplomasi untuk pengembangan ekonomi kreatif dilakukan dengan kebijakan atau aksi, seperti Seoul Music Festival pada aspek musik, Seoullo 7017 pada aspek drama, dan Seoul Fashion Week pada aspek fashion. Strategi yang dilakukan oleh pemerintah Kota Metropolitan Seoul juga dilihat dari tujuan dan kepentingan Kota Metropolitan Seoul, yaitu dengan adanya peran dari K-Pop Idol, K-Drama, dan desainer lokal di Kota Metropolitan Seoul untuk memperkenalkan Kota Metropolitan Seoul terhadap publik global, sehingga penulis berpendapat bahwa pemerintah Kota Metropolitan Seoul dapat mengoptimalisasikan potensi yang dimiliki dengan melakukan kebijakan atau aksi untuk menarik perhatian publik global.

\section{REFERENSI}

Agency, Y. N. (2019). Seoul city gov't to hold K-pop festival at Gwanghwamun Square. En.Yna.Co.Kr.

https://en.yna.co.kr/view/AEN20190917005100315

Bocella, Nicola; Salerno, I. (2016). Creative Economy Cultural Industries and Local Development (pp. 291-296).

Burhan, Z. (2017). Analisis Kebijakan Pemerintah Kota Makassar terkait Sektor Ekonomi Kreatif Berbasis Budaya dan Potensi Pengembangannya dalam Menghadapi Masyarakat Ekonomi ASEAN. Jurnal Transformasi Global.

Byeonghee, K. (2018). Seoul Brand Story. 162-163. http://www.kleenex.com/NA/About/Brand-Story.aspx Kleenex history

Delanova, M. O., Utami Effendi, M. V., \& Djemat, Y. O. (2018). Kerjasama Sister City Pemerintah Kota Bandung (Indonesia) Dan Pemerintah Kota 
Petaling Jaya (Malaysia) Dalam Meningkatkan Industri Ekonomi Kreatif Bandung Tahun 2012-2016. Jurnal Dinamika Global, 3(01), 94-107. https://doi.org/10.36859/jdg.v3i01.58

Government, S. M. (n.d.-a). A New Foothold to Leap Forward in the World. English.Seoul.Go.Kr.

http://english.seoul.go.kr/policy-information/culture-tourism/iseoulu/ne w-foothold-leap-forward-world/

Government, S. M. (n.d.-b). I Seoul U. English.Seoul.Go.Kr.

Government, S. M. (2010). Seoul designated as UNESCO Creative City for design. English.Seoul.Go.Kr.

Government, S. M. (2011a). Seoul Metropolitan Government Promotes Hallyu to Mark Export of Hit Drama. English.Compass.Kr.

Government, S. M. (2011b). Seoul Metropolitan Government Teams Up with K-Pop Stars to Promote City to Hallyu Fans. English.Seoul.Go.Kr.

Government, S. M. (2019). Seoul Hosts 2020 S/ S Seoul Fashion Week. English.Seoul.Go.Kr.

Grydehøj, A. (2014). Goals , Capabilities , and Instruments of Paradiplomacy By Subnational Jurisdictions. Local Actions in a Global Context: Paradiplomacy by Subnational Jurisdictions, 10-20. http://www.informaworld.com/openurl?genre=article\&doi $=10.1080 / 09668$ $13032000084028 \&$ magic $=$ crossref $\% 7 \mathrm{C} \% 7 \mathrm{CD} 404 \mathrm{~A} 21 \mathrm{C} 5 \mathrm{BB} 053405 \mathrm{~B} 1 \mathrm{~A} 640$ AFFD44AE3\%5Cnhttp://dx.doi.org/10.1080/0966813032000084028

Harikesa, I. W. A. (2020). Industry Revolution 4.0: Strenghthening the Creative Economy Sectors Through Bekraf Implementation Programs. Jurnal Dinamika Global, 5(01), 84-108. https://doi.org/10.36859/jdg.v5i1.139

Hönke, J. (2014). Development and international relations. Methods and Perspectives in Intellectual Property, January 2013, 243-244. https://doi.org/10.4337/9781783470532.00018

Hye Eun, K. (2015). An Analysis of the Strengths and Weaknesses of Seoul Fashion Week with a Focus on Organisational Issues. Fashion \& Textile Journal, 17(6).

Jhoo, D. (2015). Seoul City, SM join hands to boost hallyu. Koreantimesus.Com. http://www.koreatimesus.com/seoul-city-sm-join-hands-to-boost-hallyu /

Jimenéz, Lorena; Kim, D.-P. (2019). No Title. Groovekorea.Com.

Kwang-Kook, Park; Wonhee, Lee; Seok-Hwan, L. (2016). Understanding Korean 
Public Administration: Lessons Learned From Practice. In Routledge.

Lamont, C. (2015). Research Methods in International Relations.

Lequesne, C., \& Paquin, S. (2017). Federalism, paradiplomacy and foreign policy: A case of mutual neglect. International Negotiation, 22(2), 183-204. https://doi.org/10.1163/15718069-22001133

Magazine, T. A. (2018). Seoul tourism that makes both residents and visitors happy. Meetingmediagroup.Com.

http://www.meetingmediagroup.com/article/seoul-tourism-that-makes-bo th-residents-and-visitors-happy

Ministry of Foreign Affairs of Republic of Korea. (n.d.). Policy Information. mofa.go.kr. http://www.mofa.go.kr/eng/wpge/m_22844/contents.do

Nye, J. S., \& Keohane, R. O. (2010). and World Relations Transnational Politics : An Introduction. World Politics, 25(3).

Organization, K. T. (2019). Travel News. English.Visitkorea.Co.Kr.

Ramsey, A. M. (2018). Internasionalisasi Budaya Industri Kreatif: Studi Komparasi Cool Japan dan Korean Wave. Jurnal Hubungan Internasional, 53(9), 1689-1699.

Rodrigues, G. M. A., \& Mattioli, T. (2017). Paradiplomacy, Security Policies and City Networks: the Case of the Mercocities Citizen Security Thematic Unit. Contexto Internacional, 39(3), 569-587. https://doi.org/10.1590/s0102-8529.2017390300006

Sangkyun, K., Long, P., \& Robinson, M. (2009). Small Screen, Big Tourism: The Role of Popular Korean Television Dramasin South Korean Tourism.

Tourism Geographies, 11(3), 308-333.

https://doi.org/ 10.1080/14616680903053334

Suciu, M.-C. (2008). The Creative Economy. Lex Et Scientia, 60(10 I), 25.

Teh, P. Y., \& Goh, H. C. (2016). Does Korean drama have a real influence? An analysis of malaysia outbound tourists to south korea. Tourism, Culture and Communication, 16(3), 147-160.

https://doi.org/10.3727/109830416X14750895902882

Throsby, D. (2008). The concentric circles model of the cultural industries. Cultural Trends, 17(3), 147-164.

https://doi.org/10.1080/09548960802361951

UNESCO. (2017). 2013-2017 Report.

Week, S. F. (2020). About SFW. Seoulfashionweek.Org. 
Wibowo, H. (2018). Pengembangan Ekonomi Kreatif Desa Melalui Badan Usaha Milik Desa (Bumdes) Menuju Koperasi Berbasis IT. Maqdis : Jurnal Kajian Ekonomi Islam, 3(1), 17-30.

World, K. (2019). Seoul city to become music hub. World.Kbs.Co.Kr. world.kbs.co.kr:

https://world.kbs.co.kr/service/contents_view.htm?lang=e\&menu_cate=en ternews\&id=\&board_seq $=370865$

Yonhap News Agency. (2019). Seoul city gov't to hold K-pop festival at Gwanghwamun Square. en.yna.co.kr. https://en.yna.co.kr/view/AEN20190917005100315 